\title{
PRODUÇÃO DE BIODIESEL A PARTIR DA TRANSESTERIFICAÇÃO DE ÓLEO DE SOJA ÁCIDO POR VIA ENZIMÁTICA EM SISTEMAS BATELADA E CONTÍNUO
}

\author{
K. C. N. R. PEDRO, C. A. HENRIQUES e M. A. P. LANGONE \\ Universidade do Estado do Rio de Janeiro, Instituto de Química, Programa de Pós Graduação em \\ Engenharia Química (PPGEQ), Rua São Francisco Xavier, 524, PHLC, IQ, sl. 310; RJ, RJ, CEP: \\ 20550-013 \\ E-mail para contato: kcnrp@yahoo.com.br
}

RESUMO - Neste trabalho foi estudada a produção de biodiesel via transesterificação enzimática do óleo de soja em sistemas batelada e contínuo. No sistema batelada foram investigados os efeitos da temperatura, do tipo de enzima (Novozym 435, Lipozyme RM-IM e Lipozyme TL-IM) e do tipo de álcool (etanol ou butanol) sobre a reação de transesterificação utilizando óleo de soja refinado. A temperatura ótima observada nas reações empregando Lipozyme TL IM e Lipozyme RM IM foi $50^{\circ} \mathrm{C}$, enquanto que com Novozym 435 foi $70^{\circ} \mathrm{C}$. Na etanólise de óleos com índices de acidez (IA) 8,5, 54,4 e 93,7, a conversão do ácido graxo livre foi superior a 90\% nas reações conduzidas com Novozym 435. No sistema contínuo, empregando reator de leito fixo, a etanólise do óleo de soja refinado foi estudada variando-se a velocidade espacial e o tipo de lipase. Nas reações com Novozym 435 e Lipozyme TL IM, os rendimentos encontrados foram 50 e 80\%, respectivamente.

\section{INTRODUÇÃO}

O biodiesel é definido como uma mistura de ésteres monoalquílicos derivados de fontes renováveis, como óleos vegetais e gorduras animais. A rota convencional de produção de biodiesel consiste na transesterificação de óleos vegetais com metanol ou etanol utilizando catalisadores homogêneos alcalinos $(\mathrm{NaOH}$ ou $\mathrm{KOH})$, com geração de glicerol como subproduto. Porém, nesse processo existe uma restrição quanto à matéria-prima, pois esta deve ser essencialmente anidra e possuir um teor de ácidos graxos livres menor que 0,5\% em massa. A presença de ácidos graxos ocasiona a reação de neutralização com o catalisador básico, que resulta na perda de catalisador e na formação de sabão, além de propiciar o aumento da viscosidade. Assim, caso a matéria-prima contenha um teor de ácidos graxos livres maior do que o especificado, é necessária a remoção dos mesmos através, por exemplo, de uma etapa preliminar de esterificação, usualmente catalisada por ácido. O emprego de óleos refinados para produção de biodiesel significa cerca de 70-95\% do custo total de produção desse biocombustível (Zhang et al., 2003).

O emprego da catálise enzimática, utilizando lipases (triacilglicerol éster hidrolases - EC 3.1.1.3), na síntese de biodiesel a partir de matérias-primas com elevado teor de ácidos graxos livres pode representar uma tecnologia atrativa, uma vez que essas enzimas são capazes de catalisar as reações de transesterificação dos triacilgliceróis e de esterificação dos ácidos graxos livres presentes 


\section{9 a 22 de outubro de 2014 \\ Florianópolis/SC}

na matéria-prima formando biodiesel. O emprego desses biocatalisadores permite que as reações sejam conduzidas em condições reacionais brandas de temperatura e de pressão, além de ocasionar a geração de um menor volume de produtos secundários e efluentes, visto que as lipases são catalisadores altamente seletivos (Robles-Medina et al., 2009). Além disso, o biocatalisador imobilizado pode ser facilmente recuperado do meio reacional e reutilizado.

Vários tipos de reatores podem ser empregados na síntese de biodiesel por via enzimática. O reator em batelada permite uma boa dispersão do álcool no óleo através da agitação mecânica, que, no entanto, pode causar, pela tensão de cisalhamento, danos ao suporte de imobilização das enzimas, reduzindo a sua vida útil. $\mathrm{O}$ emprego de reator em leito fixo permite a condução do processo em modo contínuo. Nesse sistema, a enzima está submetida à baixa tensão de cisalhamento, o que aumenta a sua estabilidade a longo prazo (Hama et al., 2011), porém, sujeita a compactação devido à pressão da coluna do leito.

Este trabalho teve como objetivo estudar a produção de biodiesel via transesterificação enzimática do óleo de soja em sistemas batelada e contínuo empregando lipases comerciais imobilizadas (Novozym 435, Lipozyme RM-IM e Lipozyme TL-IM).

\section{EXPERIMENTAL}

\subsection{Preparo do óleo de soja ácido}

O óleo de soja ácido foi preparado adicionando-se ácido oleico (85\%, Vetec Química Fina Ltda, Brasil) ao óleo de soja refinado (Sadia, Brasil) de forma a se obter três níveis de índice de acidez (IA): 8,5; 54,4 e 93,7 (mg de KOH/g de óleo). O óleo de soja refinado apresentou índice de acidez de 0,5.

\subsection{Lipases comerciais}

As lipases comerciais utilizadas foram: Novozym 435 (lipase de Candida antarctica, imobilizada em resina acrílica macroporosa), Lipozyme RM-IM (lipase de Rhizomucor miehei, imobilizada em resina de troca iônica) e Lipozyme TL-IM (lipase de Thermomyces lanuginosus, imobilizada em sílica), todas da Novozymes Latin America Ltda (Araucária, Brasil).

\subsection{Determinação das atividades de esterificação e de transesterificação das lipases}

As atividades de esterificação e de transesterificação das lipases foram determinadas pela taxa inicial de reação. Para a atividade de esterificação foram empregados o ácido oleico e o butanol, razão estequiométrica dos reagentes (razão molar ácido oleico/butanol $=1$ ), $3 \% \mathrm{~m} / \mathrm{m}$ de enzima imobilizada, a $45^{\circ} \mathrm{C}$, de acordo com o método descrito por Souza et al. (2009). A atividade de transesterificação foi determinada utilizando trilaurina e etanol, a $50^{\circ} \mathrm{C}$, razão estequiométrica dos reagentes (razão molar trilaurina/etanol $=3$ ) e $5 \% \mathrm{~m} / \mathrm{m}$ de enzima imobilizada de acordo com o método de Correa et al. (2011). Uma unidade de atividade (U) foi definida como a quantidade de enzima que consome $1 \mu \mathrm{mol}$ de substrato por minuto por grama de preparação enzimática. 


\section{9 a 22 de outubro de 2014 \\ Florianópolis/SC}

\subsection{Efeito da temperatura, do tipo de lipase e da acidez do óleo de soja na reação de síntese de biodiesel em reator batelada}

A reação de transesterificação entre o óleo de soja e o álcool (etanol e butanol) foi conduzida nas temperaturas de 50,60 e $70^{\circ} \mathrm{C}$, utilizando razão molar óleo/álcool 1:3, 5\% $\mathrm{m} / \mathrm{m}$ de enzima imobilizada (Novozym 435, Lipozyme RM-IM e Lipozyme TL-IM), com adição escalonada do álcool (1/3 do volume total adicionado nos tempos 0,30 e $60 \mathrm{~min}$ ). O efeito do tipo de lipase e da acidez do óleo de soja foram investigados nas reações de transesterificação entre o óleo de soja ácido (óleo com IA de 0,5, 8,5, 54,4 e 93,7) e o etanol empregando razão estequiométrica dos reagentes molar (razão molar óleo:etanol = 1:3 e ácido oléico: etanol =1:1), com adição escalonada do álcool (1/3 do volume total adicionado nos tempos 0, 30 e $60 \mathrm{~min}$ ), $5 \% \mathrm{~m} / \mathrm{m}$ de lipase (Novozym 435, Lipozyme RM-IM e Lipozyme TL-IM), a $50^{\circ} \mathrm{C}$. As reações foram conduzidas em reator batelada fechado de capacidade de $15 \mathrm{~mL}$ provido de agitação magnética e condensador. O acompanhamento do teor em biodiesel nas amostras, de $20 \mu \mathrm{L}$, retiradas em duplicata do meio reacional, foi realizado por cromatografia em fase gasosa.

\subsection{Efeitos da velocidade espacial dos reagentes e do tipo de lipase empregada na síntese de biodiesel em sistema contínuo}

As reações de síntese enzimática de biodiesel em sistema contínuo foram realizadas em um reator de leito fixo com $10 \mathrm{~cm}$ de altura e $1,0 \mathrm{~cm}$ de diâmetro interno com volume total de 7,5 mL. O aparato experimental era constituído de um tanque de alimentação de vidro encamisado com volume total de $500 \mathrm{~mL}$ e de um reator de vidro encamisado (reator de leito fixo). A influência da velocidade espacial dos reagentes e da lipase empregada (Lipozyme RM IM, Lipozyme TL IM e Novozym 435) na síntese de biodiesel foi investigada nas reações a $50^{\circ} \mathrm{C}$, a coluna do reator foi preenchida com cerca de $0,7 \mathrm{~g}$ de lipase comercial imobilizada, representando uma altura de leito de $5 \mathrm{~cm}$. Para cada preparação enzimática, as velocidades espaciais dos reagentes testadas foram de 0,255 e $0,508 \mathrm{~h}^{-1}$.

\subsection{Análise cromatográfica}

Alíquotas de $20 \mu \mathrm{L}$ do meio reacional foram diluídas em $480 \mu \mathrm{L}$ hexano, contendo heptadecanoato de metila (padrão interno), e injetadas no cromatógrafo a gás VARIAN, modelo CP 3380, equipado com detector de ionização de chama (FID) e uma coluna capilar CP WAX 52 CB de $30 \mathrm{~m} \mathrm{X} \mathrm{0,25} \mathrm{mm} \mathrm{X} \mathrm{0,25 \mu m,} \mathrm{em} \mathrm{sistema} \mathrm{de} \mathrm{injeção} \mathrm{split} \mathrm{com} \mathrm{vazão} \mathrm{de} \mathrm{1:20.} \mathrm{As} \mathrm{temperaturas} \mathrm{do}$ injetor e do detector foram mantidas a $280^{\circ} \mathrm{C}$ e a $300^{\circ} \mathrm{C}$, respectivamente. A temperatura do forno foi, inicialmente, de $200^{\circ} \mathrm{C}$ e, em seguida, aumentada a uma taxa de $20^{\circ} \mathrm{C}$ por minuto até $250^{\circ} \mathrm{C}$, mantendo-se constante por 5 minutos. Hidrogênio foi o gás de arraste utilizado na vazão de $2 \mathrm{~mL} / \mathrm{min}$ e a pressão da coluna foi mantida constante em 20 psi. Um computador equipado com o software Star Workstation 6.2 foi conectado ao cromatógrafo através do módulo de interface Star 800 para integração automática dos picos obtidos. 


\section{RESULTADOS E DISCUSSÃO}

\subsection{Atividades de esterificação e de transesterificação}

Os valores das atividades de esterificação e de transesterificação das lipases comerciais imobilizadas empregadas no presente trabalho estão apresentados na Tabela 1.

Tabela 1 - Atividades de esterificação e de transesterificação das lipases

\begin{tabular}{|c|c|c|}
\hline Lipase & Atividade de esterificação (U/g) & Atividade de transesterificação (U/g) \\
\hline Novozym 435 & 3824 & 3115 \\
\hline Lipozyme RM IM & 1909 & 662 \\
\hline Lipozyme TL IM & 699 & 3972 \\
\hline
\end{tabular}

Estes resultados indicam o maior potencial catalítico da lipase Novozym 435 em reações de esterificação, seguido pela Lipozyme RM IM. Já a lipase Lipozyme TL IM apresentou um baixo valor de atividade de esterificação. Nas reações de transesterificação, as lipases Lipozyme TL-IM e Novozym 435 apresentaram os maiores valores de atividade.

\subsection{Efeito da temperatura, do tipo de lipase e da acidez do óleo de soja na reação de síntese de biodiesel em reator batelada}

Os resultados obtidos no estudo do efeito da temperatura na síntese de biodiesel a partir da reação de transesterificação do óleo de soja com o álcool (etanol e butanol) são apresentados na Figura 1.

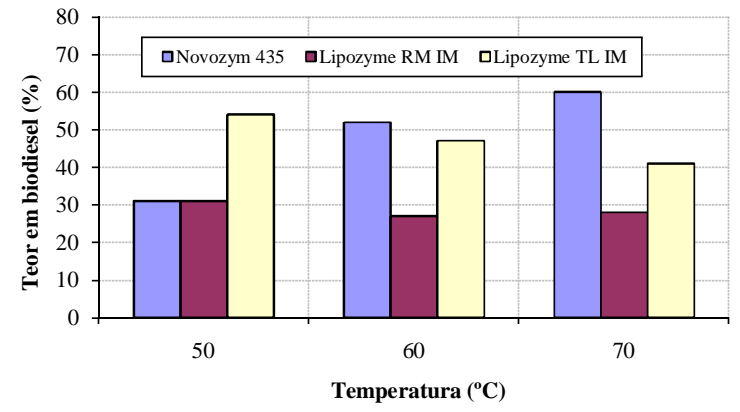

(a) Etanol

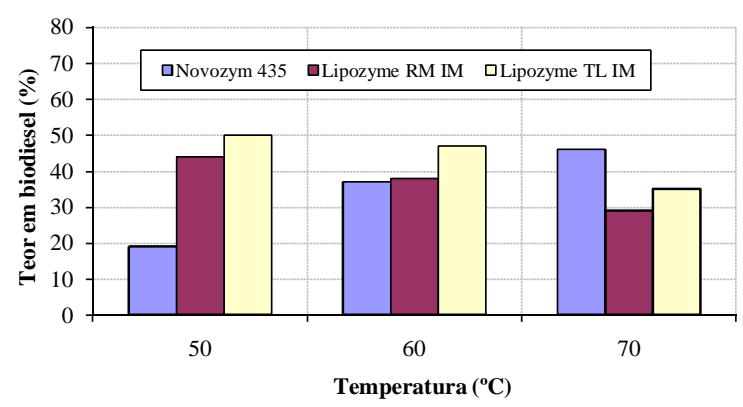

(b) Butanol

Figura 1-Teor em ésteres alquílicos na reação de transesterificação entre o óleo de soja e o álcool ((a) etanol; (b) butanol) após 4 h de reação. Condições da reação: razão molar óleo de soja:álcool 1:3, com adição escalonada de álcool (1/3 em 0 h, $1 / 3$ após 0,5 h e 1/3 após 1 h) $5 \% \mathrm{~m} / \mathrm{m}$ de biocatalisador. 
Nas reações com Novozym 435 ocorreu um aumento do teor em biodiesel com o aumento da temperatura, independente do álcool empregado. O maior teor em ésteres alquílicos foi alcançado na temperatura de $70^{\circ} \mathrm{C}$. Ao contrário, com as lipases Lipozyme RM-IM e Lipozyme TL-IM, o teor em biodiesel diminuiu com o aumento da temperatura, provavelmente devido à desnaturação da enzima. Esse comportamento também foi observado por Hernandez-Martín e Otero (2008) que verificaram que a elevação da temperatura ocasiona a desnaturação da enzima, uma vez que as ligações químicas responsáveis pela manutenção da estrutura tridimensional são alteradas. Considerando os resultados obtidos, os experimentos subsequentes foram feitos a $50^{\circ} \mathrm{C}$ para minimizar a desnaturação térmica da Lipozyme RM IM e TL IM.

O efeito da acidez do óleo de soja na síntese enzimática de biodiesel foi investigado na reação de transesterificação entre o óleo de soja ácido com índices de acidez de 8,5; 54,4 e 93,7 e o etanol. As reações também foram conduzidas com o óleo de soja refinado (IA de 0,5 ). Os resultados obtidos estão ilustrados na Figura 2.

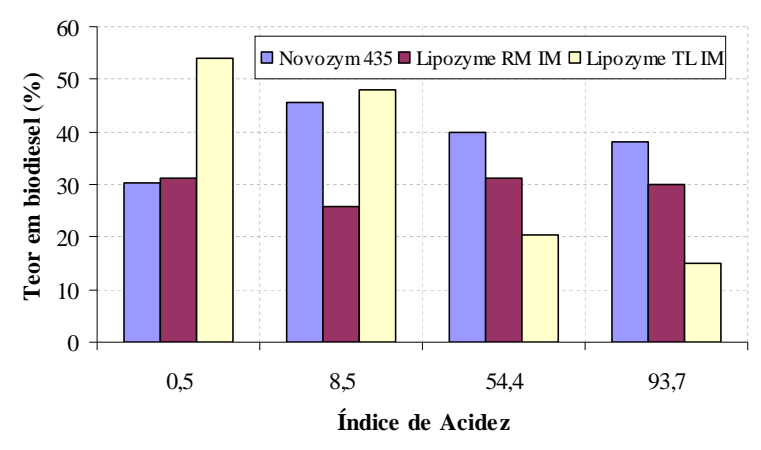

Figura 2 - Teor de biodiesel na reação de transesterificação entre o óleo de soja ácido e etanol após 4 h de reação. Condições da reação: Temperatura de $50^{\circ} \mathrm{C}$, razão molar óleo de soja:etanol 1:3, razão molar ácido oléico:etanol 1:1, com adição escalonada de etanol (1/3 em 0h, 1/3 após 0,5 h e 1/3 após $1 \mathrm{~h}) 5 \% \mathrm{~m} / \mathrm{m}$ de biocatalisador.

De acordo com os resultados apresentados na Figura 2, observa-se que a Lipozyme TL-IM apresentou teor em biodiesel, próximo a 50\%, na reação com óleo de soja com índice de acidez de 8,5, porém para índices de acidez maiores, o teor em biodiesel diminuiu. Por outro lado, o desempenho da Lipozyme RM-IM não foi influenciado pelo aumento da quantidade de ácido oleico no óleo, já que o teor em biodiesel manteve-se em torno de 30\% para todos os níveis de índice de acidez investigados. Para a Novozym 435, uma ligeira queda no teor em biodiesel, de 45 para 38\%, foi observada com o aumento da quantidade de ácido oleico adicionada ao óleo de soja refinado. $\mathrm{O}$ melhor desempenho desta enzima pode ser justificado considerando-se as elevadas atividades de esterificação $(3301 \mathrm{U} / \mathrm{g})$ e de transesterificação $(3115 \mathrm{U} / \mathrm{g})$ apresentadas por esse biocatalisador. 


\subsection{Efeitos da velocidade espacial dos reagentes e do tipo de lipase empregada na síntese de biodiesel em sistema contínuo}

O efeito da velocidade espacial foi investigado nas reações de transesterificação entre o óleo de soja refinado e o etanol no reator de leito fixo empregando as velocidades espaciais (do meio reacional composto por óleo de soja e etanol na razão molar de 1:3) de 0,255 e 0,508 $\mathrm{h}^{-1}$, utilizando um leito catalítico de $0,7 \mathrm{~g}$ de lipase ( $5 \mathrm{~cm}$ de altura). Na Figura 3 são apresentados os teores em biodiesel obtidos nesses experimentos.

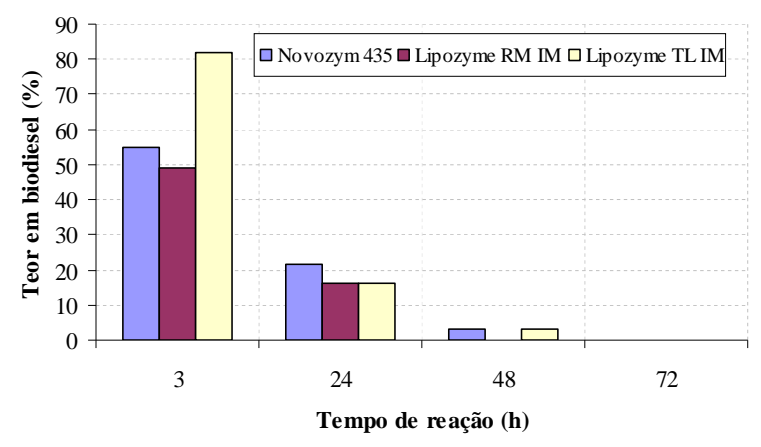

(a) $0,255 \mathrm{~h}^{-1}$

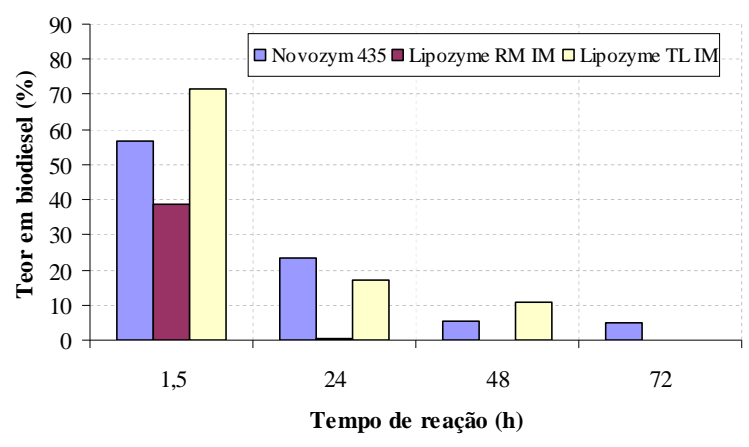

(b) $0,508 \mathrm{~h}^{-1}$

Figura 3 - Influência da velocidade espacial no teor em biodiesel na reação de transesterificação entre o óleo de soja e o etanol, em um reator de leito fixo utilizando um leito catalítico de $5 \mathrm{~cm}$ de altura da lipase (Novozym 435, Lipozyme RM IM e Lipozyme TL IM) e velocidade espacial de (a) $0,255 \mathrm{~h}^{-1}$ e de (b) $0,508 \mathrm{~h}^{-1}$, a $50^{\circ} \mathrm{C}$.

Para os três biocatalisadores estudados, observa-se uma perda importante da atividade ao longo da reação, particularmente para tempos superiores a $24 \mathrm{~h}$. A Lipozyme TL IM mostrou-se a mais ativa para o estudo da reação em leito fixo, sendo a atividade favorecida pela redução na velocidade espacial para o menor tempo de reação. Esta maior atividade estaria relacionada à maior atividade de transesterificação apresentada por esta enzima (Tabela 1). Para a lipase Novozym 435, a velocidade espacial teve efeito pouco importante sobre a atividade, no caso do menor tempo de reação. Como nos experimentos empregando Lipozyme TL IM, para o tempo de reação de 24 h, observa-se uma redução no teor em biodiesel, independente da velocidade espacial empregada. Para tempos de reação maiores, esta diminuição é mais acentuada na velocidade espacial de $0,255 \mathrm{~h}^{-1}$ para as duas enzimas. Como esperado, os menores teores em biodiesel foram observados na reação catalisada pela Lipozyme RM IM, que apresentou a menor atividade de transesterificação. Esta enzima mostrou-se também a menos estável, não apresentando atividade para o tempo de reação de $24 \mathrm{~h}$, na reação conduzida com a maior velocidade espacial.

A queda no teor em biodiesel observada ao longo da reação, particularmente após 24 h, para as lipases Novozym 435, Lipozyme RM-IM e Lipozyme TL-IM pode ser explicada pela baixa solubilidade do glicerol na mistura de produtos. Segundo Xu et al. (2011), haveria o acúmulo do 


\section{9 a 22 de outubro de 2014 \\ Florianópolis/SC}

glicerol sobre o suporte do biocatalisador, o que causaria um forte efeito negativo, reduzindo a atividade da enzima. De acordo com Dossat et al. (1999), este efeito poderia ser atribuído à formação de um filme hidrofílico (deposição do glicerol no suporte da enzima) ao redor da enzima, resultando em limitações difusionais do substrato hidrofóbico da fase orgânica para os sítios ativos da enzima. Outros autores apresentam justificativas diversas para a redução na atividade do catalisador enzimático. Assim, Chen e Wu (2003) propuseram que a perda de atividade poderia ocorrer devido ao fato do suporte (resina acrílica) adsorver componentes polares como o etanol, provocando a inativação da lipase, enquanto Watanabe et al. (2000) sinalizaram um outro problema, a migração do álcool não reagido do meio reacional para a camada de glicerol formado que cobre a lipase imobilizada, resultando na inativação da lipase pela alta concentração local do álcool, efeito este que seria potencializado no reator contínuo.

\section{CONCLUSÃO}

O estudo da influência da temperatura nas reações de transesterificação enzimática empregando óleo de soja refinado e os alcoóis etanol e butanol sinalizou que a melhor temperatura para a condução das reações empregando os biocatalisadores Lipozyme RM IM e Lipozyme TL IM foi a temperatura de $50^{\circ} \mathrm{C}$, já para a lipase Novozym 435 a temperatura que possibilitou os maiores rendimentos foi a de $70^{\circ} \mathrm{C}$. A elevação da temperatura nas reações de síntese de biodiesel ocasionou a desnaturação dos biocatalisadores Lipozyme RM IM e Lipozyme TL IM. A avaliação da influência da acidez do óleo de soja nas reações de transesterificação com etanol catalisadas por lipases imobilizadas mostrou que é possível a utilização de matérias-primas com valores elevados de índice de acidez na síntese de biodiesel. A lipase Novozym 435 apresentou o maior teor em biodiesel (superior a $35 \%$ ) na reação de etanólise do óleo de soja, a $50^{\circ} \mathrm{C}$, com óleos com índice de acidez de 8,5; 54,4 e 93,7. Deste modo, as lipases comerciais imobilizadas podem ser utilizadas na produção de biodiesel a partir de óleos com elevados índices de acidez que representam uma matéria-prima barata, através de um processo ambientalmente aceitável. Os teores em biodiesel obtidos no processo contínuo para tempos de reação curtos foram maiores que os encontrados para o sistema batelada. Uma possível justificativa seria o fato da lipase não estar exposta ao cisalhamento causado pelo agitador magnético no reator batelada, que ocasiona danos ao suporte, levando à diminuição da atividade catalítica pela redução da área superficial e consequente redução no número dos sítios catalíticos. No entanto, a produção de biodiesel em sistema contínuo (leito fixo) apresentou uma queda significativa no rendimento para tempos de reação maiores, tanto pelo acúmulo do glicerol sobre o suporte enzimático, bloqueando o acesso aos sítios ativos, como pela inativação da enzima em função do acúmulo de etanol não reagido, seja pela adsorção no suporte seja pela interação com a camada de glicerol. 


\section{REFERÊNCIAS}

CHEN, J. W.; WU, W. T. Regeneration of immobilized Candida antarctica lipase for transesterification. J. Biosci. Bioeng., v. 95, n. 5, p. 466-469, 2003.

CORRÊA I. N. S., SOUZA S. L., CATRAN M., BERNARDES O. L., PORTILHO M. F., LANGONE, M. A. P. (2011). Enzymatic Biodiesel Synthesis Using a Byproduct Obtained from Palm Oil Refining. Enzyme Res. 2011, p. 1-8, 2011.

DOSSAT, V.; COMBES, D.; MARTY, A. Continuous enzymatic transesterification of high oleic sunflower oil in a packed-bed reactor: influence of the glycerol production. Enzyme Microb.Tech., v. 25, n. 3-5, p. 194-200, 1999.

HAMA, S.; TAMALAMPUDI, S.; YOSHIDA, A.; TAMADANI, N.; KURATANI, N.; NODA, H.; FUKUDA, H.; KONDO, A. Enzymatic packed-bed reactor integrated with glycerol-separating system for solvent-free production of biodiesel fuel. Biochem. Eng. J., v. 55, p. 66-71, 2011.

HERNÁNDEZ-MARTÍN, E.; OTERO, C. Different enzyme requirements for the synthesis of biodiesel: Novozym 435 and Lipozyme TL IM. Bioresource Technol., v. 99, p. 277-286, 2008.

ROBLES-MEDINA, A.; GONZALEZ-MORENO, P. A.; ESTEBANCERDAN, L.; MOLINAGRIMA, E. Biocatalysis: Towards ever greener biodiesel production. Biotechnol. Adv., v. 27, $\mathrm{n}$. 4, p. 398-408, 2009.

SOUZA M. S.; AGUIEIRAS, E. C. G.; SILVA, M. A. P; LANGONE, M. A. P. Biodiesel synthesis via esterification of feedstock with high content of free fatty acids. Appl. Biochem.Biotech., v. 154, p. 253-267, 2009.

WATANABE, Y.; SHIMADA, Y.; SUGIHARA, A.; NODA, H.; FUKUDA, H.; TOMINAGA, Y. Continuous production of biodiesel fuel from vegetable oil using immobilized Candida antarctica lipase. J. Am. Chem. Soc., v. 77, n. 4, p. 355-360, 2000.

XU, Y.; NORDBLAD, M.; NIELSEN, PER, M.; BRASK, J.; WOODLEY, J. M. In situ visualization and effect of glycerol in lipase-catalyzed ethanolysis of rapeseed oil. J. Mol. Catal. B-Enzym., v. 72, p. 213-219, 2011.

ZHANG, Y.; DUBÉ, M. A.; MCLEAN, D. D.; KATES, M. Biodiesel production from waste cooking oil: economic assessment and sensitivity analysis. Bioresource Technol., v. 90, p. 229-240, 2003. 